\begin{tabular}{|c|c|c|}
\hline \multirow{3}{*}{$\begin{array}{r}\text { Case Reports in } \\
\text { Gastroenterology }\end{array}$} & \multirow{2}{*}{\multicolumn{2}{|c|}{ Case Rep Gastroenterol 2014;8:329-336 }} \\
\hline & & \\
\hline & $\begin{array}{l}\text { DOI: } 10.1159 / 000369129 \\
\text { Publisned online: October } 28,2014\end{array}$ & $\begin{array}{l}\text { ○ } 2014 \text { S. Karger AG, Basel } \\
\text { 1662-0631/14/0083-0329 } \$ 39.50 / 0 \\
\text { www.karger.com/crg }\end{array}$ \\
\hline & \multicolumn{2}{|c|}{$\begin{array}{l}\text { This is an Open Access article licensed under the terms of the Creative Commons } \\
\text { Attribution-NonCommercial } 3.0 \text { Unported license (CC BY-NC) (www.karger.com/OA } \\
\text { license), applicable to the online version of the article only. Distribution permitted for non } \\
\text { commercial purposes only. }\end{array}$} \\
\hline
\end{tabular}

\title{
Eosinophilic Granulomatosis with Polyangiitis and Diffuse Gastrointestinal Involvement
}

\author{
Diana L. Franco $^{a} \quad K^{2}$ in Ruff ${ }^{b} \quad$ Lester Mertz $^{c} \quad$ Dora M. Lam-Himlin ${ }^{d}$ \\ Russell Heigh ${ }^{b}$ \\ ${ }^{a}$ Department of Internal Medicine, ${ }^{b}$ Division of Gastroenterology, ${ }^{c}$ Department of \\ Rheumatology and ${ }^{\mathrm{d}}$ Department of Pathology and Lab Medicine, Mayo Clinic, Arizona, \\ Scottsdale, Ariz., USA
}

\section{Key Words}

Eosinophilic granulomatosis with polyangiitis - Gastrointestinal tract · Small bowel obstruction · Cholangitis

\begin{abstract}
Eosinophilic granulomatosis with polyangiitis (EGPA), formerly named Churg-Strauss syndrome, is a rare systemic small- and medium-sized-vessel vasculitis, characterized by the presence of severe asthma as well as blood and tissue eosinophilia. Gastrointestinal (GI) symptoms, like diarrhea and abdominal pain, are common; however, there are few reports of histologic evidence of GI involvement. We report the case of a patient on treatment for EGPA who presented with recurrent small bowel obstruction and choledocholithiasis. Biopsies of the esophagus, small bowel and common bile duct showed diffuse eosinophilia, with clear EGPA in the GI tract. Improved awareness of GI EGPA may allow for timely management of this disorder.

(c) 2014 S. Karger AG, Basel
\end{abstract}

\section{Introduction}

Eosinophilic granulomatosis with polyangiitis (EGPA), formerly named Churg-Strauss syndrome, is a rare systemic small- and medium-sized-vessel vasculitis, characterized by the presence of severe asthma as well as blood and tissue eosinophilia. It is one of the less common vasculitides with a prevalence that ranges from 10.7 to 13 cases/million inhabitants [1]. Characteristic histopathologic features include necrotizing vasculitis in veins or arteries with infiltration mainly by eosinophils in vessels and surrounding tissues. Gastro-

Diana L. Franco

Mayo Clinic, Arizona

13400 E. Shea Blvd

Scottsdale, AZ 85259 (USA)

E-Mail franco.diana@mayo.edu 
Franco et al.: Eosinophilic Granulomatosis with Polyangiitis and Diffuse Gastrointestinal Involvement

intestinal (GI) involvement has been reported to occur in approximately $50 \%$ of EGPA patients; however, there are few reports of histologic evidence of GI involvement. Symptoms include abdominal pain, vomiting and diarrhea. Few reports have described the actual pathology as it is difficult to document, but the small bowel is most commonly affected, followed by the stomach and colon. We report the case of a patient on treatment for EGPA who presented with recurrent small bowel obstruction and choledocholithiasis.

\section{Case Presentation}

A 64-year-old gentleman with a past medical history significant for EGPA presented to our gastroenterology clinic after recurrent episodes of partial small bowel obstruction within a period of 6 weeks. The diagnosis of EGPA had been done 12 years before when he presented with asthma exacerbation associated with extremity petechiae, purpura and digital infarcts as well as amaurosis and temporal artery swelling. Two years previous to his presentation, the patient had several times undergone endoscopic retrograde cholangiopancreatography (ERCP) for recurrent choledocholithiasis with associated cholangitis. Biopsies had shown acute and chronic inflammation with reactive epithelial changes presumably secondary to stones. The vasculitis had been stable on methotrexate and prednisone with serial stable inflammatory markers and absolute eosinophils prompting a reduction in immune suppression 3 months prior to presentation.

On presentation, the patient was having recurrent, episodic abdominal pain associated with intermittent abdominal distention and new lower extremity purpuric lesions. Physical examination was otherwise within normal limits. Elevated inflammatory markers and eosinophilia of $0.69 \times 10^{9} / 1(13.5 \%)$ were detected. Magnetic resonance enterography was performed to further evaluate the cause of the recurrent small bowel obstruction. It showed bowel wall thickening in the distal small bowel, with mechanical small bowel obstruction proximal to the ileocecal valve (fig. 1). Given his history of recurrent cholangitis, ERCP with cholangiogram was performed which showed moderate dilation of the biliary tree. Cholangioscopy showed a nodular common bile duct, with one stone in the left intrahepatic duct which was successfully removed. Common bile duct biopsies showed eosinophils and mononuclear cells with some associated fibrosis (fig. 2).

Extended enteroscopy was performed to evaluate the upper GI tract. Erythematous mucosa in the gastric fundus and body, nodular mucosa in the gastric antrum and multiple small duodenal polyps were identified. The esophagus, the remaining duodenum and the jejunum were normal. Biopsies of the normal and diseased mucosa showed a diffuse dense inflammatory infiltrate in the lamina propria including mononuclear cells and eosinophils ( $>50$ eosinophils per high-power field). On immunohistochemistry, $\mathrm{T}$ and B cells showed normal immunophenotype, and in situ hybridization for Epstein-Barr virus was negative, findings that ruled out lymphoma.

Retrograde balloon-assisted enteroscopy showed congested and thickened folds of the mucosa in the distal ileum biopsies with normal colon. Pathology showed blunted villi, with an inflammatory expansion of the lamina propria including the presence of increased eosinophils (fig. 3). Table 1 summarizes the macroscopic and pathologic findings.

Magnetic resonance angiography was performed and no signs of significant mesenteric artery stenosis or other vascular abnormality were identified. All findings were consistent with Churg-Strauss syndrome involving the GI tract even though no vasculitis was shown on pathology. Although surgery of the ileal stricture was considered, medical management with increased dose of methotrexate and prednisone was elected. Unfortunately, after 2 months 
Franco et al.: Eosinophilic Granulomatosis with Polyangiitis and Diffuse Gastrointestinal Involvement

of being totally asymptomatic on higher-dose immune suppression the patient experienced a syncopal event and died. Clinically, this was attributed to known pre-existing heart disease likely due to EGPA involvement.

\section{Discussion}

EGPA, formerly known as Churg-Strauss syndrome, was first described in 1951 by Jacob Churg and Lotte Strauss as a form of vasculitis that included necrotizing vasculitis, eosinophilic infiltrates and granulomata [2]. Although it is classified as a vasculitis, the affected tissue usually does not show necrotizing vasculitis or granulomata, but rather an apparently nondestructive infiltration of the vessel walls by eosinophils; in fact, only $40-60 \%$ of patients with EGPA have anti-neutrophil cytoplasmic antibodies (ANCAs) [3, 4]. For this reason the diagnostic criteria remain clinical (table 2). Our patient had negative ANCAs but a clinical diagnosis of EGPA. EGPA is one of the less common vasculitides with a prevalence ranging from 10.7 to 13 cases/million inhabitant, and three disease phases have been proposed: (1) a prodromal phase that is characterized by atopic disease, (2) an eosinophilic phase, with blood eosinophilia, and (3) a vasculitic phase, with eosinophilia involving medium- and small-sized vessels [5, 6]. GI involvement may precede or present concurrent with the vasculitic phase.

The respiratory tract is almost constantly involved, but any organ system can be affected. Of all the systemic manifestations, GI involvement has a negative prognostic factor, especially if mesenteric infarction and bowel perforation are present [7]. GI involvement has been reported to occur in approximately $50 \%$ of patients with a diagnosis of EGPA, symptoms including abdominal pain, vomiting and diarrhea [8]. For few cases the actual pathology has been described as it is difficult to document. Pathologic findings include multiple ulcerations, perforation, obstruction and ileus with documented eosinophilia and granulomata. Ischemic changes in the GI tract are rarely documented as the GI tract has a robust collateral blood supply reducing the incidence of ischemia. Histologic vasculitis is rarely seen on biopsy sections as endoscopic biopsies are too superficial to adequately sample submucosal vessels [8].

Although eosinophilic infiltration of the GI tract can represent a spectrum of pathologic conditions, including EGPA and hypereosinophilic syndrome, our patient fulfilled the clinical criteria for EGPA, and although no vasculitis was documented in this patient's biopsies, the eosinophilia was sufficient for the diagnosis. The lack of vasculitis could be attributed to the aforementioned sampling issues related to endoscopic biopsy. Alternatively, perhaps this patient had not yet progressed from the eosinophilic phase to a vasculitic phase. Previous reports have shown that the small bowel is the most commonly involved region of the GI tract, followed by the stomach and the colon [9]. Our patient's GI compromise was remarkable because of its diffuse distribution, including the biliary tree. Biopsies of the common bile duct showed inflammation which could be attributed to EGPA, as published cases have documented acalculous cholecystitis associated with this type of vasculitis [10,11]. However, the exact etiology of the common bile duct changes in our patient remained unclear, as he also had documented recurrent episodes of choledocholithiasis, which may have similar histologic findings. Treatment of the vasculitis includes corticosteroids, but usually during a flair, steroids with cytotoxic medications are required to induce remission. Depending on the degree of GI involvement, patients may require surgical resection; this is an indicator of poor prognosis [12]. 
Franco et al.: Eosinophilic Granulomatosis with Polyangiitis and Diffuse Gastrointestinal Involvement

In summary, the diagnosis of EGPA in the GI tract requires high clinical suspicion as histologic documentation of vasculitis may be unavailable and eosinophilia may be the only finding. Improved awareness of GI EGPA may allow for timely management of this disorder.

\section{References}

1 Mouthon L, Dunogue B, Guillevin L: Diagnosis and classification of eosinophilic granulomatosis with polyangiitis (formerly named Churg-Strauss syndrome). J Autoimmun 2014;48-49:99-103.

-2 Churg J, Strauss L: Allergic granulomatosis, allergic angiitis, and periarteritis nodosa. Am J Pathol 1951;27: 277-301.

-3 Sablé-Fourtassou R, Cohen P, Mahr A, Pagnoux C, Mouthon L, Jayne D, Blockmans D, Cordier JF, Delaval P, Puechal X, Lauque D, Viallard JF, Zoulim A, Guillevin L; French Vasculitis Study Group: Antineutrophil cytoplasmic antibodies and the Churg-Strauss syndrome. Ann Intern Med 2005;143:632-638.

-4 Schmitt WH, Csernok E, Kobayashi S, Klinkenborg A, Reinhold-Keller E, Gross WL: Churg-Strauss syndrome: serum markers of lymphocyte activation and endothelial damage. Arthritis Rheum 1998;41:445-452.

-5 Mahr A, Guillevin L, Poissonnet M, Ayme S: Prevalences of polyarteritis nodosa, microscopic polyangiitis, Wegener's granulomatosis, and Churg-Strauss syndrome in a French urban multiethnic population in 2000: a capture-recapture estimate. Arthritis Rheum 2004;51:92-99.

6 Lanham JG, Elkon KB, Pusey CD, Hughes GR: Systemic vasculitis with asthma and eosinophilia: a clinical approach to the Churg-Strauss syndrome. Medicine (Baltimore) 1984;63:65-81.

7 Calabrese LH, Hoffman GS, Guillevin L: Therapy of resistant systemic necrotizing vasculitis. Polyarteritis, Churg-Strauss syndrome, Wegener's granulomatosis, and hypersensitivity vasculitis group disorders. Rheum Dis Clin North Am 1995;21:41-57.

8 Kim YB, Choi SW, Park IS, Han JY, Hur YS, Chu YC: Churg-Strauss syndrome with perforating ulcers of the colon. J Korean Med Sci 2000;15:585-588.

-9 Murakami S, Misumi M, Sakata H, Hirayama R, Kubojima Y, Nomura K, Ban S: Churg-Strauss syndrome manifesting as perforation of the small intestine: report of a case. Surg Today 2004;34:788-792.

10 Nishie M, Tomiyama M, Kamijo M, Kannari K, Tanosaki M, Baba M, Matsunaga M, Suda T: Acute cholecystitis and duodenitis associated with Churg-Strauss syndrome. Hepatogastroenterology 2003;50:998-1002.

-11 Imai H, Nakamoto Y, Nakajima Y, Sugawara T, Miura AB: Allergic granulomatosis and angiitis (Churg-Strauss syndrome) presenting as acute acalculous cholecystitis. J Rheumatol 1990;17:247-249.

12 Berarducci M, Thomas C, Kay J: Churg-Strauss syndrome with diffuse gastrointestinal involvement. J Clin Rheumatol 1996;2:221-226.

13 Masi AT, Hunder GG, Lie JT, Michel BA, Bloch DA, Arend WP, Calabrese LH, Edworthy SM, Fauci AS, Leavitt RY, et al: The American College of Rheumatology 1990 criteria for the classification of Churg-Strauss syndrome (allergic granulomatosis and angiitis). Arthritis Rheum 1990;33:1094-1100. 
Franco et al.: Eosinophilic Granulomatosis with Polyangiitis and Diffuse Gastrointestinal Involvement

Table 1. Macroscopic and microscopic involvement

\begin{tabular}{|c|c|c|}
\hline GI tract & Macroscopic finding & Pathology \\
\hline Esophagus & normal & $\begin{array}{l}\text { intense eosinophilic infiltrate through the glandular } \\
\text { epithelium and lamina propria }\end{array}$ \\
\hline Stomach fundus & erythema & $\begin{array}{l}\text { intense eosinophilic infiltrate through the glandular } \\
\text { epithelium and lamina propria }\end{array}$ \\
\hline Stomach body & nodular mucosa & $\begin{array}{l}\text { intense eosinophilic infiltrate through the glandular } \\
\text { epithelium and lamina propria }\end{array}$ \\
\hline Stomach antrum & nodular mucosa & $\begin{array}{l}\text { intense eosinophilic infiltrate through the glandular } \\
\text { epithelium and lamina propria }\end{array}$ \\
\hline Duodenum & multiple polyps & $\begin{array}{l}\text { intense eosinophilic infiltrate through the glandular } \\
\text { epithelium and lamina propria }\end{array}$ \\
\hline Jejunum & normal & $\begin{array}{l}\text { intense eosinophilic infiltrate through the glandular } \\
\text { epithelium and lamina propria }\end{array}$ \\
\hline Ileum & thickened fold of the mucosa & $\begin{array}{l}\text { intense eosinophilic infiltrate through the glandular } \\
\text { epithelium and lamina propria }\end{array}$ \\
\hline Colon & normal & $\begin{array}{l}\text { intense eosinophilic infiltrate through the glandular } \\
\text { epithelium and lamina propria and blunted villi }\end{array}$ \\
\hline Biliary tree & nodular mucosa, diffuse dilation & eosinophilic infiltrate with associated fibrosis \\
\hline
\end{tabular}

Table 2. Diagnostic criteria (Churg-Strauss syndrome: American College of Rheumatology classification criteria [13])

Asthma

Eosinophilia

History of allergy

Pulmonary infiltrates, non-fixed

Paranasal sinus abnormalities

Extravascular eosinophils

Four out of six criteria should be present. 
Franco et al:: Eosinophilic Granulomatosis with Polyangiitis and Diffuse Gastrointestinal Involvement

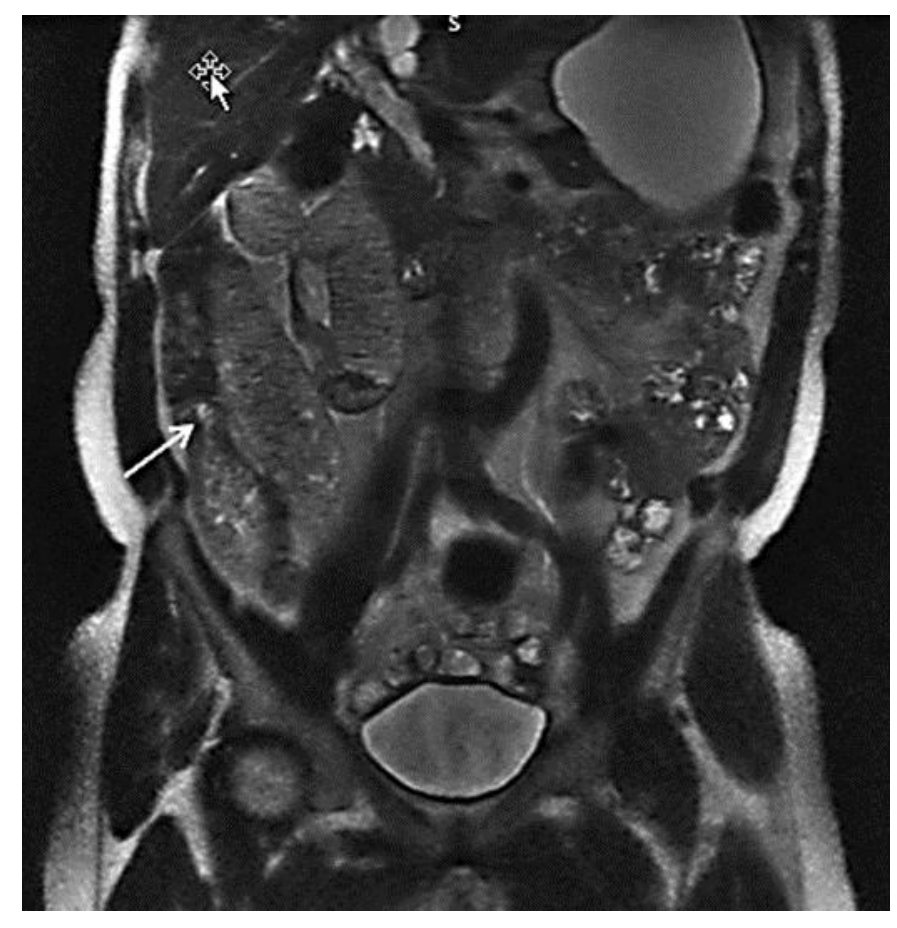

Fig. 1. Magnetic resonance enterography. The arrow points to the distal small bowel thickening due to mechanical obstruction proximal to the ileocecal valve. 


\begin{tabular}{ll|l} 
Case Reports in & \multicolumn{2}{l}{ Case Rep Gastroenterol 2014;8:329-336 } \\
\cline { 2 - 3 } Gastroenterology & DOI: 10.1159/000369129 & $\begin{array}{l}\text { @ 2014 S. Karger AG, Basel } \\
\text { www.karger.com/crg }\end{array}$ \\
\hline
\end{tabular}

Franco et al.: Eosinophilic Granulomatosis with Polyangiitis and Diffuse Gastrointestinal Involvement
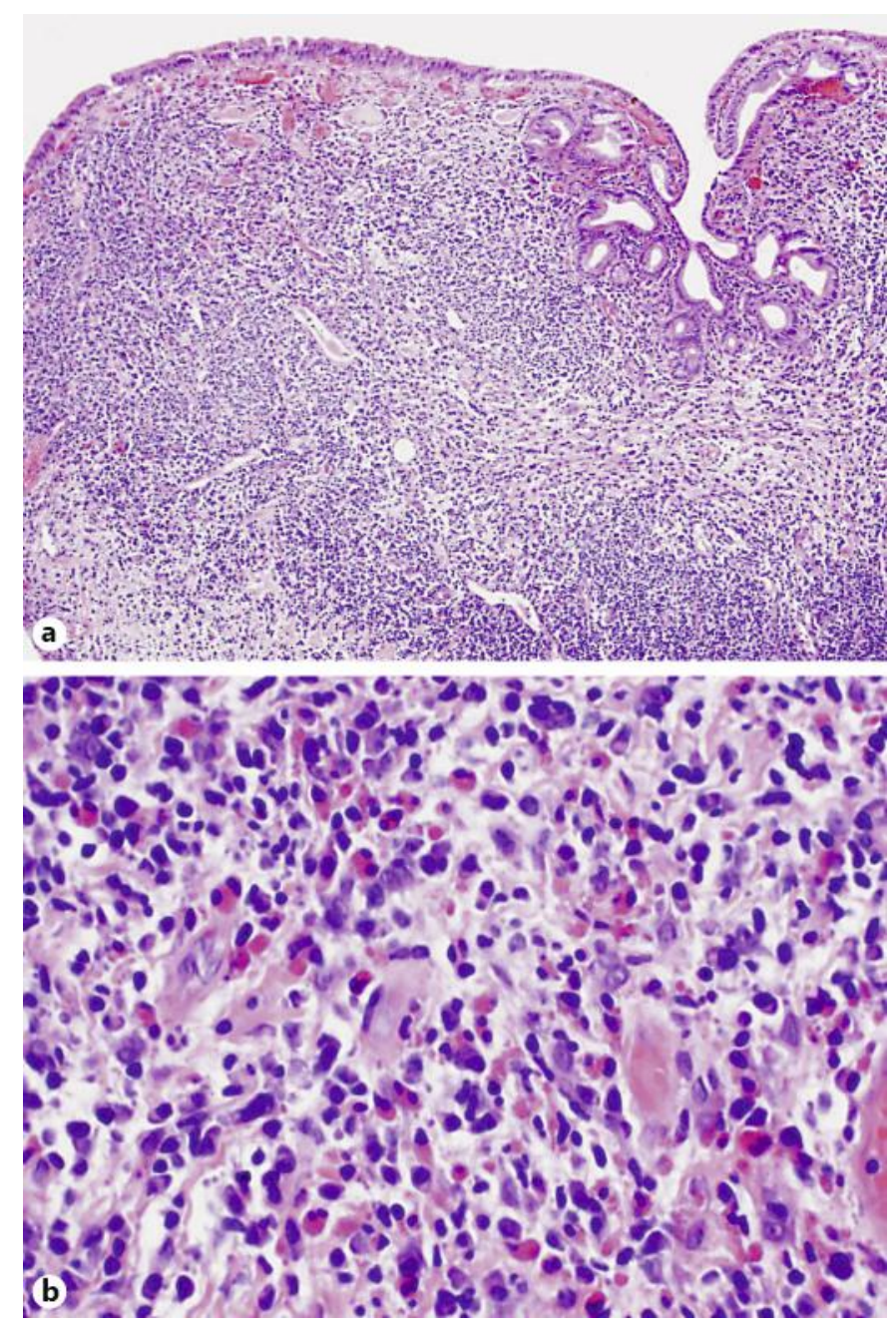

Fig. 2. a 10× magnification. Hematoxylin \& eosin stain of the common bile duct shows marked expansion of the lamina propria with chronic inflammation (original magnification 100×). b 60 times higher magnification shows that the inflammatory infiltrate is composed of mixed chronic inflammatory cells including plasma cells, lymphocytes, and a striking increase in bright pink eosinophils (original magnification $600 \times)$. 


\begin{tabular}{rll} 
Case Reports in & \multicolumn{2}{l}{ Case Rep Gastroenterol 2014;8:329-336 } \\
\cline { 2 - 3 } Gastroenterology & DOI: 10.1159/000369129 & $\begin{array}{l}\text { ○ 2014 S. Karger AG, Basel } \\
\text { www.karger.com/crg }\end{array}$ \\
\hline
\end{tabular}

Franco et al.: Eosinophilic Granulomatosis with Polyangiitis and Diffuse Gastrointestinal Involvement
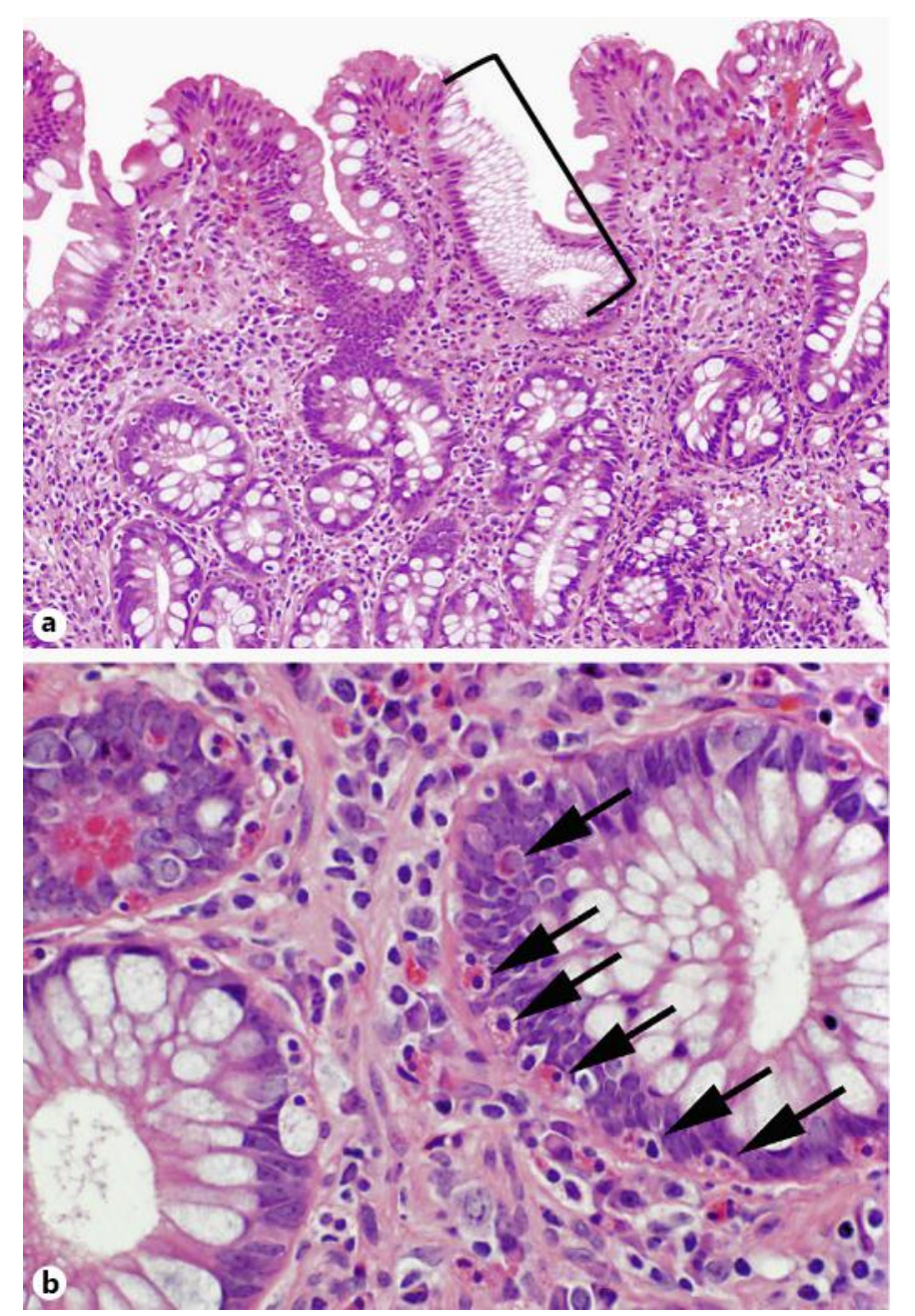

Fig. 3. a 20x magnification. Hematoxylin \& eosin stain of the ileum shows features of chronic damage including mild villous blunting and mucinous metaplasia of the surface epithelium (bracket). Note also the mild expansion of the lamina propria by inflammatory cells (original magnification $200 \times$ ). b $60 \times$ magnification. While scattered, single eosinophils are a normal finding in the crypt epithelium, this example shows an increase of intraepithelial eosinophils with multiple eosinophils crossing the basement membrane, some of which are back-to-back (arrows) (original magnification 600x). 